\title{
Systems biology analyses of the dynamic host response to Toxoplasma gondii infection in a murine model
}

\author{
MEE TECK KHO ${ }^{1}$, CHUN WIE CHONG ${ }^{2}$, ERIN SWEE HUA LIM ${ }^{3}$, \\ NOR HADIANI ISMAIL ${ }^{4}$, LACHLAN OLIVER DRAPER ${ }^{5}$, WAI KEAT YAM ${ }^{2}$, \\ PATRICIA KIM CHOOI LIM ${ }^{1}$, JOON WAH MAK ${ }^{1}$ and IVAN K. S. YAP ${ }^{2} *$ \\ ${ }^{1}$ School of Postgraduate Studies, Institute for Research, Development and Innovation, International Medical University, \\ 126 Falan Falil Perkasa 19, Bukit Falil, 57000 Kuala Lumpur, Malaysia \\ ${ }^{2}$ Life Sciences Department, School of Pharmacy, International Medical University, 126 falan Jalil Perkasa 19, Bukit \\ Falil, 57000 Kuala Lumpur, Malaysia \\ ${ }_{3}^{3}$ Perdana University, Block B \& D Aras 1, MAEPS Building, MARDI Complex, Falan MAEPS Perdana, 43400 \\ Serdang, Selangor DE, Malaysia \\ ${ }^{4}$ Atta-ur-Rahman Institute for Natural Products Discovery, Universiti Teknologi MARA, 42300 Bandar Puncak Alam, \\ Selangor DE, Malaysia \\ ${ }^{5}$ School of Medicine, International Medical University, 126 Falan Falil Perkasa 19, Bukit Falil, 57000 Kuala Lumpur, \\ Malaysia
}

(Received 27 fanuary 2016; revised 5 May 2016; accepted 30 May 2016)

\section{SUMMARY}

Toxoplasmosis affects a third of the global population and is of particular concern for immunologically compromised individuals. Toxoplasmosis induces host physiological events ranging from immunological to metabolic responses across multiple biological compartments. To understand the sequence of host responses during acute and chronic Toxoplasma gondii infection, eight male BALB/c mice were infected with 2000 T. gondii ME49 tachyzoites with a further eight uninfected mice used as controls. Plasma cytokines status, urinary metabolic profiling and fecal microbial profiles were characterized to monitor temporal variation related to T. gondii infection. The results showed elevated serum interferon- $\gamma$ (IFN- $\gamma$ ), interleukin-12p40 and necrosis factor- $\alpha$ during acute phase of infection with concomitant perturbation in host energy metabolism and host-gut microbiome co-metabolism of phenolics and a shift in microbial composition. However, the differences were less pronounced during the putative chronic phase of infection with elevated IFN- $\gamma$, differences in urinary $\mathrm{N}$-acetyls and $\mathrm{O}$-acetyls of glycoproteins with no shift in gut microbial composition. Structural equation modelling on the current data showed host immune responses as the main driver for changes observed in urinary metabolites and gut microbial composition. Such an approach can be applied to other models of infectious diseases to aid understanding of host-pathogen interactions and potential biomarker discovery.

Key words: host-pathogen interactions, structural equation modelling, systems biology, Toxoplasma gondii.

\section{INTRODUCTION}

Toxoplasmosis, one of the most common parasitic diseases worldwide, is caused by the protozoan Toxoplasma gondii. It is a parasite with no specific host and has more than one obligatory host in its life cycle (Tenter et al. 2000). The only known definitive host of $T$. gondii is the Felidae family mainly wild and domestic cats. $T$. gondii has several potential routes of transmission within or between host species that can be either vertical (transplacentally via tachyzoites) or horizontal (orally via ingestion of $T$. gondii at various stages of its life cycle) transmission (Tenter et al. 2000). Humans are usually infected through ingestion of oocysts from contaminated food or water or by contact with cats. Toxoplasma gondii is prevalent in

* Corresponding author: Life Sciences Department, School of Pharmacy, International Medical University, 126 Jalan Jalil Perkasa 19, Bukit Jalil, 57000 Kuala Lumpur, Malaysia. Tel. +60 32731 7474. E-mail: ivan_yap@imu.edu.my most parts of the world with an estimated one third of the global human population infected (Montoya and Liesenfeld, 2004). Toxoplasma gondii infection may cause miscarriage, stillbirth or congenital disease in its hosts, thus it is of importance to the medical and veterinary world.

Metabolic profiling approaches were first introduced into parasitology in an initial study on Schistosoma mansoni-infected mice (Wang et al. 2004). Since then, metabolic profiling strategy has been used to investigate other rodent host-parasite models including Schistosoma japonicum-hamster (Wang et al. 2006), and Trypanosoma brucei brucei-mouse (Wang et al. 2008) with the aim of characterizing the metabolic responses of hosts to these parasites at the molecular level. Although such single matrix/platform approach allowed for comprehensive characterization of hostparasite interaction from the metabolic perspective, a combination of different sample matrices, analysed using different platforms, will enable a more holistic understanding of such complex biological interactions involving multiple levels of biological complexities.

Parasitology Open (2016), Vol. 2, e9; page 1 of 13. (C) Cambridge University Press 2016. This is an Open Access article, distributed under the terms of the Creative Commons Attribution licence (http://creativecommons.org/licenses/by/4.0/), which permits unrestricted re-use, distribution, and reproduction in any medium, provided the original work is properly cited. 
Correlating immune response to an invading organism as well as to changes in the host metabolic profile can give new insights into immunological processes (Lamour et al. 2015) and may contribute to new developments in early diagnosis, therapy and immune-prevention. Monitoring of changed biochemical pathways will help to discover the factors responsible for either disease susceptibility (Lamour et al. 2015) or resistance (Canuto et al. 2014).

Cell-mediated immune (CMI) response is of particular importance in infection with intra-cellular parasites and is the major mechanism of resistance against T. gondii (Wong and Remington, 1993). In addition, resistance in mice after $T$. gondii infection was dependent on both $\mathrm{CD}^{+}$and $\mathrm{CD}^{+} \mathrm{T}$ lymphocytes (Hakim et al. 1991). In vivo treatment with either recombinant interleukin (IL)-12, interferon$\gamma(\mathrm{IFN}-\gamma)$, necrosis factor- $\alpha$ (TNF- $\alpha)$, IL- $1 \alpha$ and IL-1 $\beta$, all cytokines of the Th1 subset, has had a protective effect against T. gondii infection (Gazzinelli et al. 1993, 1994). Synthesis of macrophage IL-10 has been shown by several studies to enable the establishment of chronic infections by different pathogens, including $T$. gondii, by avoiding the induction of an excessively strong CMI and thus allowing the parasite to persist in the vertebrate host (Fiorentino et al. 1991). Furthermore, T. gondii infection results in significant mucosal response with $\operatorname{IgM}$ detected 1-2 months after infection followed by IgA and a vigorous $\mathrm{IgG}$ antibody response was observed in patients with acute toxoplasmosis (Turunen et al. 1983). Despite enormous progress in toxoplasmosis research and understanding the genome (Boyle et al. 2006) and proteome (Zhou et al. 2004) of T. gondii, more work is needed to ascertain the complex developmental changes within different hosts once $T$. gondii is established. The host metabolic response to $T$. gondii infection and the ensuing systematic and metagenomic responses to parasitic nutrient demand and survival will require systems biology approaches to delineate the effect and ascertain the role of each biological compartment to parasitic insult. Correlation between the host metabolic, metagenomic and immune responses to parasitic infection may lead to new insights into host-parasite interactions (Lamour et al. 2015). A plethora of cofactors involved in signal transduction and epigenetic changes of T. gondii are essentially by-products of metabolic pathways such as amino acids and lipid pathways (Kim and Weiss, 2008).

The current study was conducted to characterize the complex host-microbiome-parasite interactions of toxoplasmosis in an experimental murine model. Here a systems biology approach was used to investigate the acute and chronic phases of $T$. gondii infection by integrating immune, metabolic and gut microbial matrices of the host particularly selected peripheral cytokines, metabolic profiles from urine, and fecal bacterial composition.
MATERIALS AND METHODS

\section{Ethics}

Animal care and handling procedures used in this study followed the guidelines and requirements of local and national authorities for the care and use of animals for scientific purposes in Malaysia. The study was approved by the Joint Committee on Research and Ethics, International Medical University, Malaysia (IMU-R-093/2012).

\section{Animal handling and sampling}

The toxoplasmosis murine model used in this study was established according to the protocol used by (Chew et al. 2012a, b). All animals used in this study were male BALB/c mice (4-5 weeks of age) purchased from a university-approved experimental animal supplier (Selangor, Malaysia). A total of 16 animals (eight controls and eight infected) were housed in groups of 4 in macrolon cages and maintained at controlled environmental conditions (temperature: $26^{\circ} \mathrm{C}$, relative humidity: $60-70 \%$, light/dark cycle: $12 / 12 \mathrm{~h}$ ) with free access to water and standard rodent chow. Mice were acclimatized for 14 days prior to the start of experiment, in order to minimize potential stress-related variation in biological profiles. For the experimental group, eight mice were infected intraperitoneally with $1 \mathrm{~mL}$ of saline solution containing $2000 \mathrm{~T}$. gondii tachyzoites (ME49 strain) each whilst the remaining eight control mice were each given $1 \mathrm{~mL}$ of saline solution intraperitoneally.

Urine, blood and fecal samples were collected one day before infection (pre-infection) and on days 7 , 14, 21, 28, 35 and 42 post-infection. Sample collection took place between 0800 and $1100 \mathrm{~h}$ to minimize diurnal variation in concentrations of biofluids. At least $50 \mu \mathrm{L}$ of urine and eight fecal pellets were collected from each mouse into Petri dishes by gently rubbing the abdomen. Sample which do not achieved targeted volume/count was excluded from the subsequent analyses. To avoid cross-contamination, new gloves and Petri dish was used for each separate animal. Urine and fecal samples were collected for one-dimensional (1D) proton nuclear magnetic resonance spectroscopy $\left({ }^{1} \mathrm{H} \quad \mathrm{NMR}\right)$-based metabolic profiling and terminal restriction fragment length polymorphism (TRFLP) analyses, respectively. Small amounts of tail blood samples $(50-80 \mu \mathrm{L})$ were collected for cytokine profiling. All samples were collected into $1.5 \mathrm{~mL}$ microcentrifuge tubes, and immediately stored at $-80^{\circ} \mathrm{C}$. Animals were weighed at each time point, using a weighing balance (Precisa, Switzerland). Cardiac puncture was performed pre-terminally on all animals 42 days post-infection (dpi) under deep anaesthesia for collection of blood. The collected blood samples were left at room temperature for clotting for at least $30 \mathrm{~min}$ and subjected to centrifugation at $1000 \mathrm{~g}$ for $10 \mathrm{~min}$. The 
sera was carefully separated from the red blood cells using a micropipette and stored at $-80{ }^{\circ} \mathrm{C}$ until further use. Brain and other organs were harvested subsequently at autopsy.

\section{Histopathology}

Mouse brain tissues harvested on day 42 were fixed in $10 \%$ neutral buffered-formalin and embedded in paraffin wax. The $4 \mu \mathrm{m}$ thick sections were stained with haematoxylin and eosin stain (Sigma Aldrich, USA) for subsequent histopathological assessment and toxoplasma cyst identification.

\section{Cytokine multiplex quantification}

A ten-plex cytokine immunoassay customized for IFN- $\gamma$, tumour necrosis factor- $\alpha(\mathrm{TNF}-\alpha)$ and a panel of IL; IL-1 $\beta$, IL-2, IL-4, IL-5, IL-6, IL-10, IL-12p40, IL-17 was carried out using the Mouse Cytokine/Chemokine Magnetic Bead Panel Kit in a 96-well plate \# MCYTOMAG-70 K (Millipore, USA) according to manufacturer's instructions, using a hand-held magnet for the washing steps. The plate was read using the Luminex 200TM Milliplex Analyser (Luminex, USA) with the Luminex Software xponentv3.1 (Luminex, USA) for data acquisition. The Median Fluorescent Intensity (MFI) data were analysed using a five-parameter logistic or spline curve-fitting method for calculating cytokine concentrations in the samples. The values were multiplied by two which was the dilution factor used for sample dilution for calculation of concentrations. The experiment was carried out in duplicates for each sample.

\section{${ }^{1}$ H NMR spectroscopy of urine}

Urine samples were prepared by mixing $20 \mu \mathrm{L}$ of urine with $30 \mu \mathrm{L}$ of a phosphate buffer containing $90 \%$ deuterated water $\left(\mathrm{D}_{2} \mathrm{O}\right)$ and $0.25 \mathrm{~mm} 3$-trimethylsilyl-1-[2,2,3,3- $\left.{ }^{2} \mathrm{H}_{4}\right]$ propionate (TSP) and left to stand for $10 \mathrm{~min}$. The resulting mixtures were then transferred into $5 \mathrm{~mm}$ NMR microbore tubes with $1.7 \mathrm{~mm}$ stem (Norell, USA).

A standard $1 \mathrm{D}{ }^{1} \mathrm{H}$ NMR spectrum was acquired for each sample with a pulse [recycle delay (RD)$90^{\circ}-t_{1}-90^{\circ}-t_{\mathrm{m}}-90^{\circ}$-acquire free induction decay (FID)] on a Bruker AVIII $600 \mathrm{MHz}$ spectrometer (Bruker Biospin, Fallenden, Switzerland) with a 5 $\mathrm{mm} \mathrm{BB}(\mathrm{F}) \mathrm{O}$ broadband probe operating at $600 \cdot 13$ $\mathrm{MHz}$ (ambient probe temperature $27^{\circ} \mathrm{C}$ ). Samples were automatically delivered to the spectrometer by a Bruker SampleCase ${ }^{\mathrm{TM}}$. The field frequency was locked on $\mathrm{D}_{2} \mathrm{O}$ solvent. The water peak was suppressed by gradient water pre-saturation during the relaxation delay (RD) of $4 \mathrm{~s}$ and mixing time $\left(t_{\mathrm{m}}\right)$, of $0.01 \mathrm{~s}$. The $90^{\circ}$ pulse length was adjusted to $\sim 10 \mu$ s and an acquisition time of $2.65 \mathrm{~s}$ was used.
In total, 32 transients were collected into $64 \mathrm{~K}$ data points using a spectral width of $20 \mathrm{ppm}$. An exponential line broadening function of $0.3 \mathrm{~Hz}$ was applied to the free induction decay prior to Fourier transformation.

\section{Fecal DNA extraction and TRFLP analyses}

DNA was extracted using QiAmp DNA stool mini kit (Qiagen, USA) according to the manufacturer's protocol. The TRFLP was carried out as described in (Chong et al. 2012) with minor modifications. Briefly, PCR was conducted using universal primers $(27 \mathrm{~F}$ and $1492 \mathrm{R})$ targeting bacterial $16 \mathrm{~S}$ rRNA gene region. Both primers were tagged with the fluorescence dye phosphoramidite fluorochrome 5-carboxyfluorescein (FAM) and 6-carboxy-hexachlorofluorescein (HEX) at 5', respectively. The amplicons were digested using a four-base cutter MSP-1 before subjected to electrophoretic separation using ABI 3100 and ABI 3730XL genetic analysers (Applied Biosystems, USA). ROX labeled GeneScan 500 control was used as size standard. The resulting fragment profiles were scored, aligned and noise filtered using the web-based programme T-REX (Culman et al. 2009). Noise filtered procedure was carried out by removing peaks, which are lower than the overall standard deviation. In addition, alignment was carried out by binning the peaks into TRFs with the clustering threshold of $0.5 \mathrm{bp}$, starting from the smallest peak among all the profiles (Smith et al. 2005).

\section{Data processing and multivariate statistical analysis}

For metabonomics analysis, ${ }^{1} \mathrm{H}$ NMR spectra of urine samples were manually phased and baselinecorrected using Bruker TopSpin (Version 3.1, Bruker Biospin, Fallenden, Switzerland). All spectra were referenced to the TSP resonance at $\delta 0 \cdot 00$. The complete spectra $(\delta 0 \cdot 0-10 \cdot 0)$ were digitized into $7 \mathrm{~K}$ data points using an in-house developed MATLAB script (O. Cloarec, Imperial College London). The region containing the water resonance $(\delta 4 \cdot 5-6 \cdot 5)$ was removed from each spectrum to eliminate baseline effects of imperfect water suppression. In addition, the regions $\delta 0 \cdot 0-0 \cdot 5$ and $\delta 9 \cdot 2-10 \cdot 0$ containing only noise were removed. For each spectrum, normalization to the total sum of the residual spectrum was carried out prior to pattern recognition analyses followed by scaling of the data to unit variance. Both unsupervised (principal component analysis, PCA) and supervised multivariate data analysis methods (projection to latent structures-discriminant analysis, PLS-DA and orthogonal partial least squares discriminant analysis, O-PLS-DA (Trygg and Wold, 2002; Cloarec et al. 2005)) were employed to visualize and interpret experimental differences. The statistical significance and validity of subsequent 
results were calculated using a permutation test (number of permutations $=1000$ ). The covariance plot was used to aid interpretation of the significance of each metabolite from the permutation tests. The colours projected onto the spectrum indicate the significance of the metabolites with blue indicating no significant difference at $P>0.05$ confidence levels and red indicating high significant difference at $P<$ $0 \cdot 05$. In this study, only metabolites with $P<0 \cdot 01$ will be considered significant.

The TRFLP data obtained from T-REX was exported into PERMANOVA + add-on of the PRIMER6 multivariate data analysis package (Plymouth Marine Laboratory, UK) for analyses. Alpha-diversity indices including Shannon diversity index $\left(H^{\prime}\right)$ and Pielou's measure of species evenness $\left(\mathfrak{F}^{\prime}\right)$ were calculated using the DIVERSE option. For multivariate-analyses, the data was pre-treated with unit variance normalization procedure before generating a Euclidean distance matrix, which was used to perform permutational multivariate analysis of variance (PERMANOVA) and PCA. The PERMANOVA was carried out to test for gut microbial compositional difference between the groupings, while the PCA was used to visualize the distribution of the sample across the sampling points. The significance of the PERMANOVA was calculated based on 999 permutations and corrected using Monte Carlo correction.

Canonical analysis of principal coordinates (CAP) is a 'constrained' ordination method which uses a priori hypotheses for dimension selection (Anderson and Willis, 2003). In this study, CAP was use to illustrate dimensions with strongest separation in relation to infection and time points.

\section{Structural equation modelling (S.E.M.)}

S.E.M. was carried out using 'Lavaan' and visualized with 'semPlot' package under R programme. (Epskamp, 2015)' (Rosseel, 2012) A total of three models were built to represent the hypothesized relationships among the measured variables under each category which make up of cytokines (immunology), NMR profiles (metabolic composition) and TRFLP profiles (gut microbial composition). Difference in the model fit was compared using chi-square different test. Model showing lowest reading for Chi-square value, Akaike information criterion (AIC) and Bayesian information criterion (BIC) scores were selected as the best-fitted model.

\section{Distance-based linear modelling (DISTLM)}

DISTLM were carried out as described in (Yap et al. 2015) Briefly, the parameters showing the most consistent responses to the corresponding overall profiles (NMR, TRFLP or cytokines) was selected using stepwise selection under the secondorder bias-corrected AIC (Yanagihara et al. 2011).

\section{RESULTS}

\section{Histology and physiological monitoring}

The mean bodyweight between control and infected mice was significant across time point $(F=11 \cdot 69, P<$ $0 \cdot 01)$ but insignificant across treatments (i.e. control $v s$ infection, $F=1 \cdot 46, P=0 \cdot 20$ ) (see Supplementary Materials Fig. S1, available from http://journals.cambridge.org/PAO). Putative chronic infection was established by day 42 as observed from the haematoxylin and eosin stained paraffinized brain tissues (Fig. 1). No brain cyst was observed from brain tissue collected from day 14.

\section{Characterization of host immune responses to parasite infection}

Pattern in overall host immune responses derived from cytokine multiplex (see Supplementary Materials Table S1, available from http://journals.cambridge.

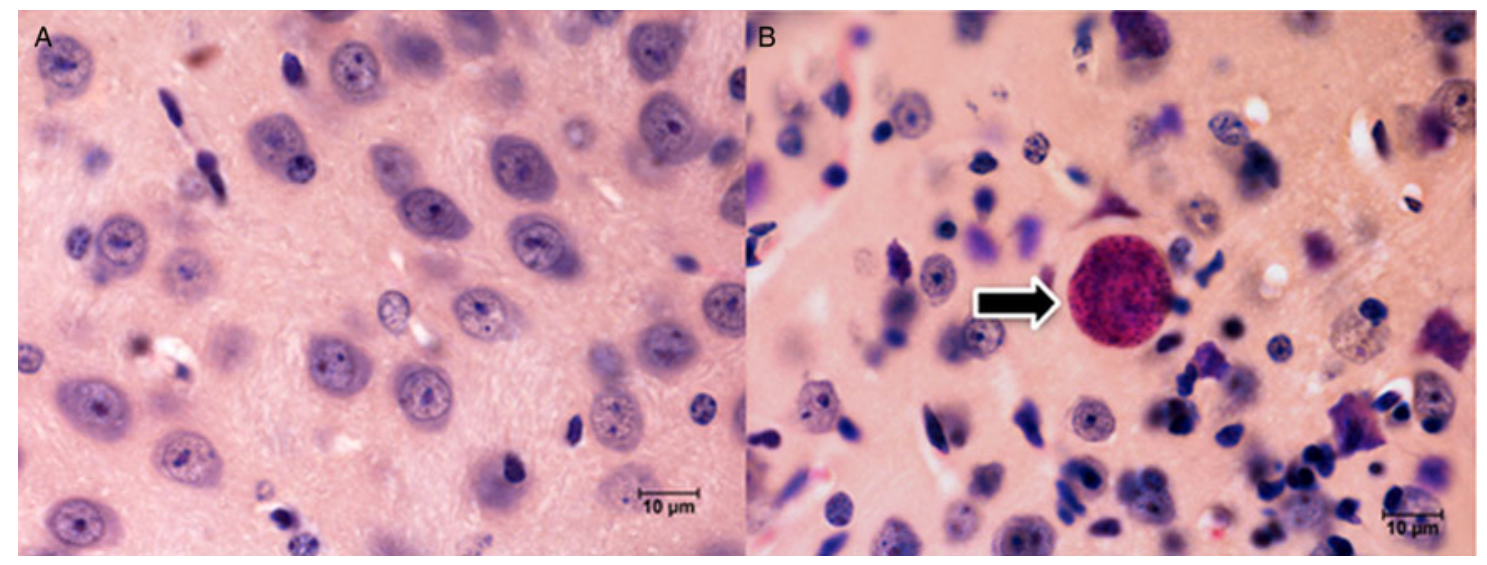

Fig. 1. Brain histopathology of control (A) vs infected (B) BALB/c mice 42 dpi. Toxoplasma gondii cysts (arrows indicate bradyzoite tissue cysts) were observed in the brains of BALB/c mice $42 \mathrm{dpi}$ (B). Footnote: The data are representative of mice in the whole experiments $[n=16$ (eight controls; eight infected)]. All tissues were $\mathrm{H}$ and E-stained and viewed at $\times 400$ magnification. 

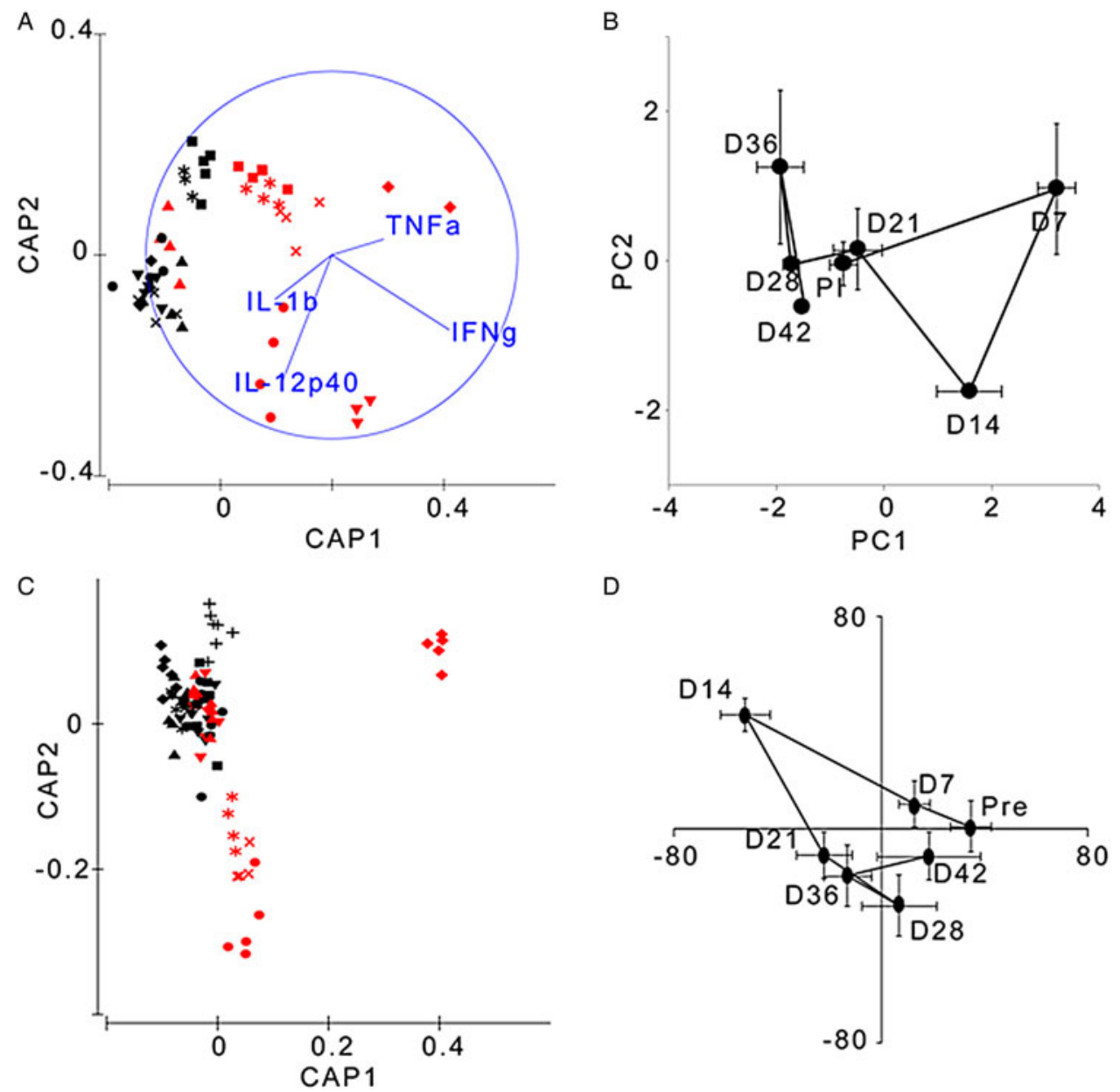

D

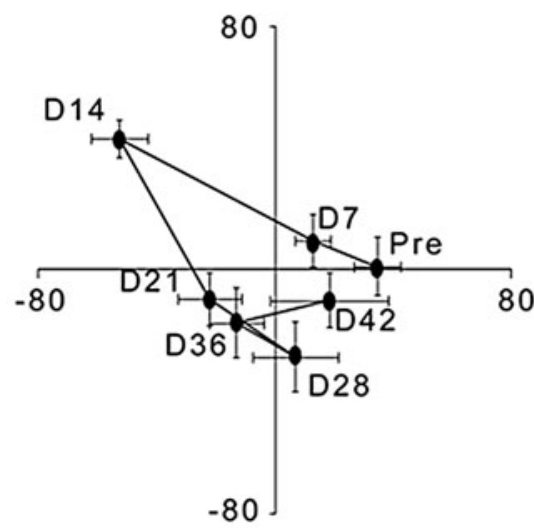

Fig. 2. (A) Canonical analysis of principal coordinates (predictive power, $Q^{2}: 46 \cdot 3 \%$ ) scores and corresponding loadings (blue subplot) plot of cytokine measurements from infected (red) and control animals (black); (B) PCA time trajectory plots derived from serum cytokine data of infected animals showing differentiation of pre-infection (PI) from post infection at each time point (days 7, 14, 21, 28, 36 and 42). (C) PCA scores plot derived from urinary ${ }^{1} \mathrm{H}$ NMR spectra of male BALB/c mice from infected and control animals. (D) Subsequent PCA mean trajectory plot derived from the urinary ${ }^{1} \mathrm{H}$ NMR spectra of infected animals only. The error bar indicates the standard error. Key: $\boldsymbol{\Delta}$, PI; $\mathbf{\nabla}$, Day $7 ; \boldsymbol{\$}$, Day 14; Day 21; +, Day 28; *, Day 36; $\mathbf{\square}$, Day 42.

org/PAO) was analysed using CAP plot (constrained analysis). In brief, the procedure selects axes showing greatest discrimination against treatments (i.e. control $v s$ infected) and time-points (days 0, 1, 7, 14, 21, 28, 36 and 42). A strong separation between control and infected animals was apparent in the first component (CAP1 - black - control vs red - infected) $(P=0 \cdot 001$, $Q^{2}=46 \cdot 3 \%$ ) (Fig. 2A). The demarcation between the control and infected animals was mainly contributed by the upregulation of IL- $1 \beta$ in the former while upregulation of IL-12p40 was observed during the acute infection phase and overall upregulation of TNF- $\alpha$ and IFN- $\gamma$ throughout the infection (vector overlay Fig. 2A). Further, among the infected group, samples from days 7 and 14 formed a distinct cluster at the bottom of the second component (CAP2). A follow-up PERMANOVA analysis exhibited a significant infection effect (pseudo- $F=9 \cdot 43, P=0 \cdot 001$ ) and significant interaction between infection and timepoints (pseudo- $F=2 \cdot 115, P=0 \cdot 022$ ) (Table 1 ). This suggested that the time-course immunological response for both groups were significantly distinct to each other. However, no significant difference was detected when comparing the pooled cytokines profiles (both control and infected groups) between different days (pseudo- $F=1 \cdot 624, P=0 \cdot 087$ ).

To understand the dynamics of host cytokine responses to $T$. gondii infection, a PCA time trajectory plot was constructed for the infected mice (Fig. 2B). The principal component time trajectory plot showed clear partitioning between samples from days 7 and 14 and that of pre-infection. However, samples from day 21 onwards converged with the cytokine levels detected during pre-infection.

\section{Characterization of host metabolic responses to parasite infection}

Initial analysis of the urinary NMR data using CAP showed clear separation between the control and 
Table 1. Permutational multivariate analysis of variance (PERMANOVA) results based on 1000 times permutation for immunological, metabolic and microbial profiles

\begin{tabular}{|c|c|c|c|c|c|}
\hline Factor(s) & $\mathrm{df}$ & SS & MS & Pseudo- $F$ & $P(\mathrm{MC})$ \\
\hline \multicolumn{6}{|c|}{ a. Immunological profiles } \\
\hline Days (Da) & 6 & $222 \cdot 61$ & $37 \cdot 101$ & $1 \cdot 6236$ & $0 \cdot 129$ \\
\hline Treatment (Tr) & 1 & $215 \cdot 5$ & $215 \cdot 5$ & $9 \cdot 4306$ & $0 \cdot 002$ \\
\hline Dax'Tr & 6 & $289 \cdot 98$ & $48 \cdot 33$ & $2 \cdot 115$ & $0 \cdot 035$ \\
\hline \multicolumn{6}{|l|}{ b. Metabolic profiles } \\
\hline $\mathrm{Da}$ & 6 & 58952 & $9825 \cdot 3$ & $1 \cdot 6673$ & $0 \cdot 001$ \\
\hline $\operatorname{Tr}$ & 1 & 20245 & 20245 & $3 \cdot 4356$ & $0 \cdot 001$ \\
\hline DaxTr & 6 & 54182 & $9030 \cdot 4$ & 1.5324 & $0 \cdot 005$ \\
\hline \multicolumn{6}{|l|}{ c. Microbial profiles } \\
\hline $\mathrm{Da}$ & 6 & 18213 & $3035 \cdot 5$ & $2 \cdot 9248$ & $0 \cdot 001$ \\
\hline $\operatorname{Tr}$ & 1 & $4279 \cdot 3$ & $4279 \cdot 3$ & $4 \cdot 1232$ & $0 \cdot 001$ \\
\hline DaxTr & 6 & 10359 & $1726 \cdot 6$ & $1 \cdot 6636$ & $0 \cdot 001$ \\
\hline
\end{tabular}

df, degree of freedom; SS, sum of square; MS, mean square.

infected animals (Fig. 2C) with the pre-infected animals overlapping with the controls along the first principal component. Subsequently, principal component mean trajectory analysis was performed on the urinary data derived from the infected groups to identify key time points where infection trajectory changes over time. The resulting mean trajectory scores plot (Fig. 2D - infected group) showed that, upon infection, the metabolic trajectory moved along the first principal component from pre-infection to day 7 . The metabolic trajectory moved further along the first principal component on day 14 . However, by day 21 , the metabolic trajectory changed direction along the first principal component, whereby the metabolic composition of samples collected from days 28, 36 and 42 clustered in the same region. The metabolic composition for day 42 was found to ordinate close to the pre-infection (Fig. 2D). Nevertheless, the corresponding PLS-DA scores plot derived from the urine NMR data of days 14 and 42 samples (Fig. 3A and B, respectively) showed clear separation between the infected and control animals indicating that the infected animals never recovered $42 \mathrm{dpi}$. The model predictive power, $Q^{2}$, was 95 and $77 \cdot 3 \%$ respectively, indicating the statistical validity of the model.

Significant metabolites partitioning according to both treatments and time-points were established

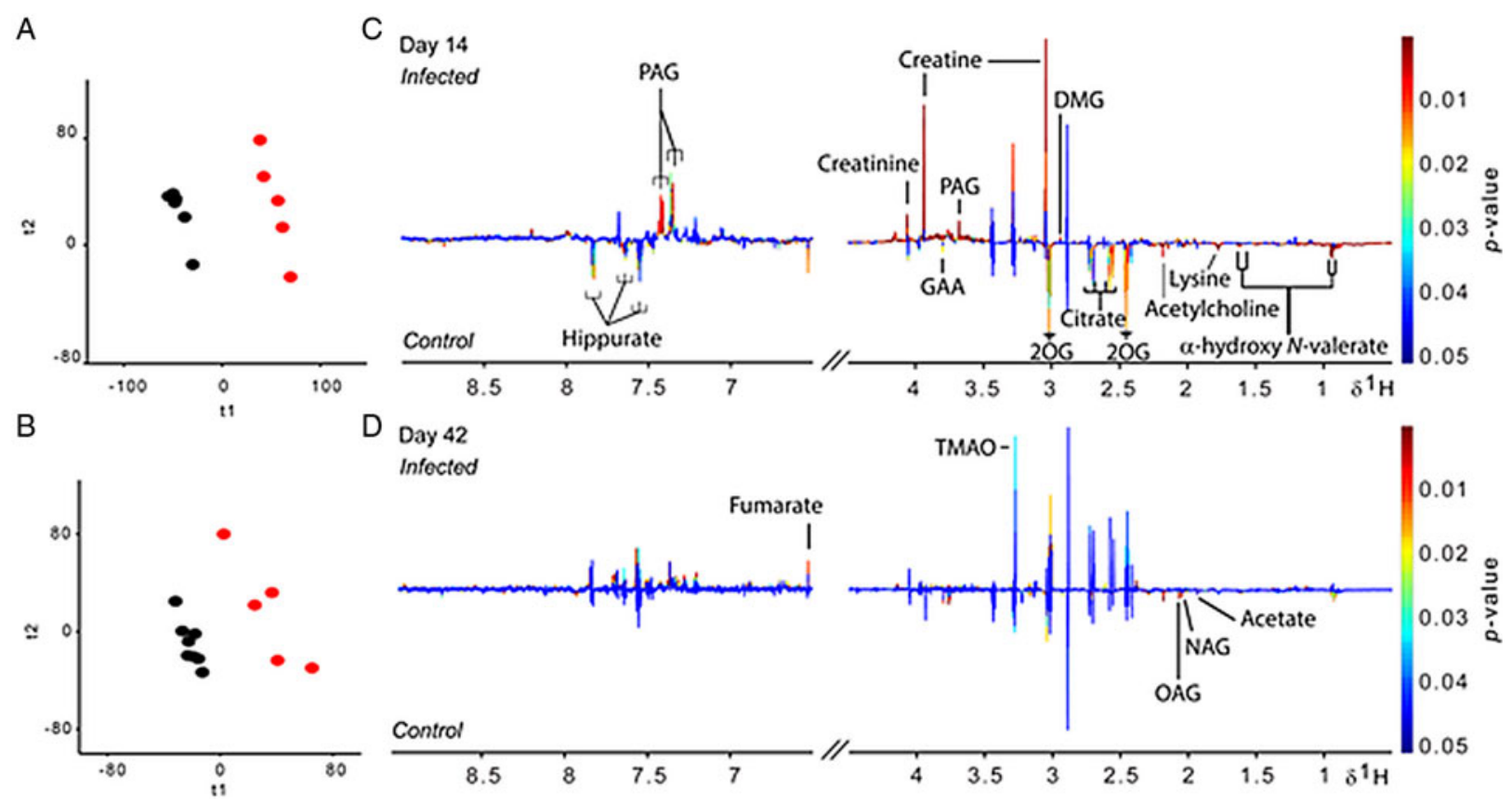

Fig. 3. PLS-DA scores plot derived from urinary ${ }^{1} \mathrm{H}$ NMR spectra of infected and control animals on (A) day 14 , and $\left.\mathrm{B}\right)$ day 42. The corresponding covariance plots showing the colour-coded significance of urinary metabolite profiles calculated using permutation test between infected and control animals on (C) day 14, and (D) day 42. Key: 2OG, 2-oxoglutarate; DMG, dimethylglycine; GAA, guanodinoacetate, NAG, $N$-acetyls of glycoproteins; OAG, $O$-acetyls of glycoproteins; PAG, phenylacetylglycine; TMAO, trimethylamine $N$-oxide 
Table 2. ${ }^{1} \mathrm{H}$ NMR-derived metabolites that differ significantly between control and infected animals on days 14 and 42

\begin{tabular}{|c|c|c|c|}
\hline \multirow[b]{2}{*}{ Metabolites } & \multirow[b]{2}{*}{$\begin{array}{l}\text { Chemical shifts, ppm } \\
\text { (multiplicity) }\end{array}$} & \multicolumn{2}{|l|}{ Time points } \\
\hline & & $\begin{array}{l}\text { Control }(n=6) \text { vs Infected } \\
(n=5) ; \text { Day } 14\left(R^{2} X=\right. \\
\left.99 \cdot 8 \% ; Q^{2} Y=93 \cdot 7 \%\right)\end{array}$ & $\begin{array}{l}\text { Control }(n=8) \text { vs Infected } \\
(n=5) ; \text { Day } 42\left(R^{2} X=\right. \\
\left.99 \cdot 7 \% ; Q^{2} Y=43 \cdot 4 \%\right)\end{array}$ \\
\hline $\begin{array}{l}\alpha \text {-hydroxy } N \text { - } \\
\text { valerate }\end{array}$ & $0 \cdot 92(\mathrm{t}), 1 \cdot 37(\mathrm{~m}), 1 \cdot 64(\mathrm{~m})$ & + & + \\
\hline 2-oxoglutarate & $2 \cdot 45(\mathrm{t}), 3 \cdot 01(\mathrm{t})$ & + & \\
\hline Acetate & $1.92(\mathrm{~s})$ & & + \\
\hline$\beta$-aminoisobutyrate & $1 \cdot 2(\mathrm{~s})$ & + & \\
\hline Citrate & $2 \cdot 55(\mathrm{~d}), 2 \cdot 65(\mathrm{~d})$ & + & \\
\hline Creatine & $3 \cdot 04(\mathrm{~s}), 3 \cdot 93(\mathrm{~s})$ & - & \\
\hline Dimethylglycine & $2 \cdot 92(\mathrm{~s})$ & - & \\
\hline $\begin{array}{l}\delta \text {-pyroline-5- } \\
\text { carboxylate* }\end{array}$ & $1 \cdot 78(\mathrm{~m}), 2 \cdot 23(\mathrm{~m})$ & + & \\
\hline Formimoglutamate & $2 \cdot 03(\mathrm{~m}), 2 \cdot 17(\mathrm{~s})$ & + & \\
\hline Fumarate & $6 \cdot 53(\mathrm{~s})$ & + & - \\
\hline Glycine & $3 \cdot 56(s)$ & & - \\
\hline Guanidinoacetate & $3 \cdot 80(\mathrm{~s})$ & + & + \\
\hline Hippurate & $3 \cdot 98(\mathrm{~d}), 7 \cdot 54(\mathrm{t}), 7 \cdot 64(\mathrm{t}), 7 \cdot 84(\mathrm{~d})$ & + & - \\
\hline Methionine & $2 \cdot 14(\mathrm{~s})$ & + & \\
\hline$N$-acetyl glutamate & $1.95(\mathrm{sb})$ & - & \\
\hline $\begin{array}{l}N \text {-acetyls of } \\
\text { glycoproteins }\end{array}$ & $2 \cdot 04(\mathrm{sb})$ & & + \\
\hline$N$-methyl nicotinate & $4 \cdot 44(\mathrm{~s}), 8 \cdot 84(\mathrm{t}), 9 \cdot 12(\mathrm{~s})$ & + & \\
\hline $\begin{array}{l}\text { O-acetyls of } \\
\text { glycoproteins }\end{array}$ & $2 \cdot 06(\mathrm{sb})$ & & + \\
\hline $\begin{array}{l}\text { Phenyalacetyl- } \\
\text { glycine }\end{array}$ & $7 \cdot 43(\mathrm{~m}), 7 \cdot 37(\mathrm{~m}), 3 \cdot 75(\mathrm{~d}), 3 \cdot 68(\mathrm{~s})$ & - & - \\
\hline Taurine & $3 \cdot 23(\mathrm{t}), 3 \cdot 43(\mathrm{t})$ & - & \\
\hline $\begin{array}{l}\text { Trimethylamine } N \text { - } \\
\text { oxide }\end{array}$ & $3 \cdot 27(\mathrm{~s})$ & - & \\
\hline
\end{tabular}

All metabolites were significant at the level of $P<0 \cdot 01$ calculated using permutation test.

s, singlet; sb, singlet broad; d, doublet; t, triplet; $m$, multiplets.

*, tentatively assigned as.

+ , relatively higher in the control group.

- , relatively lower in the control group.

based on PERMANOVA (pseudo- $F=1 \cdot 66$ and $3 \cdot 44$ respectively, $P=0 \cdot 001)$. In addition, contrasting temporal response pertinent to the status of infection (control $v s$ infected) was also detected (interaction pseudo- $F=1.53, P=0.005$ ) (Table 1). Statistical significance of the urinary metabolites was calculated using permutation test (number of permutations $=$ 1000). Only metabolites with a $P$-value of 0.01 and below were selected and summarized in Table 2 . Figure $3 \mathrm{C}$ and D show the corresponding covariance plots of control $v s$ infected animals derived from urinary samples obtained from days 14 and 42 . Urine collected from mice on day 14 showed elevated $\alpha$-hydroxy $N$-valerate, 2 -oxoglutarate, $\beta$-aminoisobutyrate, citrate, acetylcholine, fumarate, guanidinoacetate, hippurate, methionine and $\mathrm{N}$ methyl nicotinate in the control group, whereas the infected group showed elevated urinary creatine, dimethylglycine, $N$-acetyl glutamate, phenyalacetylglycine, taurine and trimethylamine $N$-oxide. In contrast, changes in urinary metabolites were less pronounced on day 42 with the control group showing higher levels of urinary $\alpha$-hydroxy $N$-valerate, acetate, guanidinoacetate, $N$-acetyls- and $O$ acetyls of glycoproteins, whereas the infected group showed higher levels of urinary fumarate, glycine, hippurate, phenyalacetylglycine and trimethylamine $N$-oxide.

\section{Characterization of host fecal microbiota composition in response to parasite infection}

Fecal bacterial richness (Shannon diversity index) and evenness (Pielou's evenness) of the experimental animals were inferred using TRFLP (see Supplementary Materials Table S2, available from http://journals.cambridge.org/PAO). Sample with more TRFs is generally considered 'richer' than sample with low TRFs count. On the other hand, community that harbour TRFs with similar intensity is considered 'more even' than community containing large number of low-intensity peaks but dominated by only a few high dominant peaks. Based on Shannon Diversity index $\left(H^{\prime}\right)$, no 


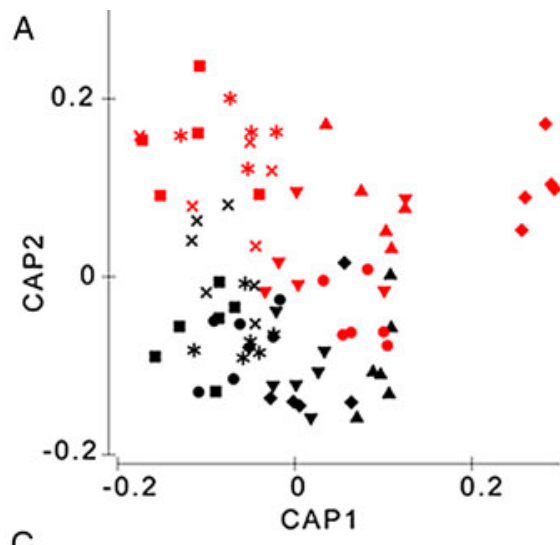

C
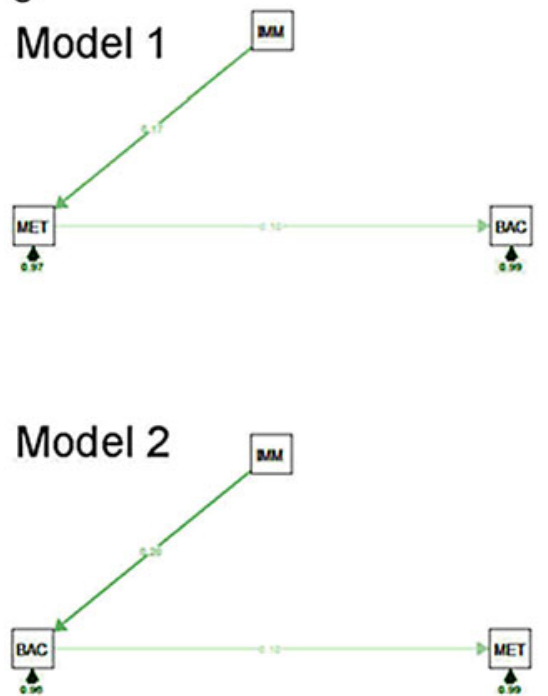
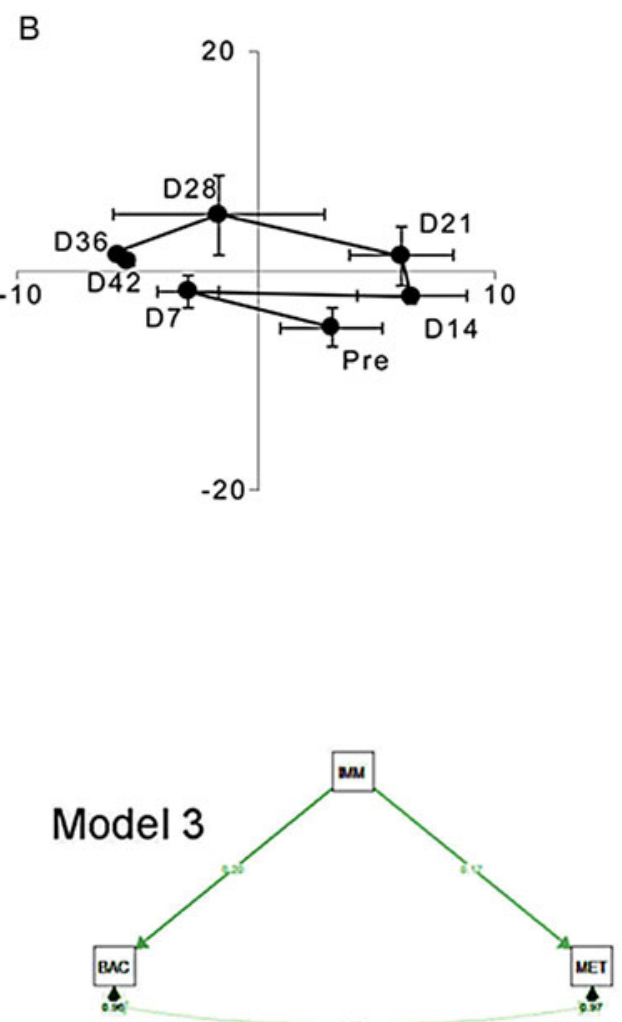

Fig. 4. (A) Canonical analysis of principal coordinates (predictive power, $Q^{2}: 30 \cdot 4 \%$ ) scores plot derived from fecal TRFLP profiles of infected and control animals. (B) PCA time trajectory plots derived from TRFP data of infected animals showing differentiation of pre-infection (PI) from post infection at each time point (days 7, 14, 21, 28, 36 and 42). (C) Causal Model derived using structural equation modelling. A total of three models were built based on the sequelae of responses from cytokines, bacterial and metabolic profiles. Among the three models, model 3 was selected as the best fit model. Key: $\boldsymbol{\Lambda}$, PI; $\mathbf{\nabla}$, Day 7; $\diamond$ Day 14; •, Day 21; +, Day 28; *, Day 36; $\mathbf{\square}$, Day 42.

significant difference in bacterial richness was detected $(T=1 \cdot 88, P=0.064)$ between the control and infected animals $\left(H^{\prime}{ }_{\text {control }}=3 \cdot 30 \pm 0.92\right.$, $\mathrm{H}_{\text {infected }}=3.06 \pm 0.92$ ). However, significant lower Pielou's evenness $\left(\mathscr{f}^{\prime}\right)$ was detected $(T=2 \cdot 67, P=$ $0.009)$ in the infected arms in comparison to the controls $\left(\mathscr{f}^{\prime}\right.$ infected $\left.0 \cdot 77 \pm 0 \cdot 01, \quad \mathscr{F}^{\prime}{ }_{\text {control }}=0 \cdot 80 \pm 0 \cdot 01\right)$. When the gut microbial distribution pattern was ordinated on the CAP plot (Figure 4A), partitioning in accordance to infection and control groups was observed on the vertical axis $\left(\mathrm{CAP} 2-P=0 \cdot 01, Q^{2}\right.$ $=30 \cdot 4 \%$ ). Further, among the infection arm, separation of samples collected on day 14 was apparent. However, the same pattern was not detectable under the PCA trajectory plot for the infection group (Figure 4B). The significance of the sample partitioning was validated using PERMANOVA (Table 1). Based on the analysis, significant effects of infection, time-points and interactions were detected (pseudo$F=1 \cdot 66-4 \cdot 12, P=0 \cdot 001)$.
Hypothesized biological causal model for Toxoplasma infection

S.E.M. was used to evaluate and compare alternative models of causal influences between immunological responses, metabolites variation and gut microbial compositional changes in relation to Toxoplasma infection. A total of three models were hypothesized: Model 1 assumed that the responses to infection followed a fixed chronological sequence starting with immune response, follow by metabolic response and lastly microbial response. Model 2 assumed that the chain of event starts with immune response; follow by microbial response and lastly metabolic response. Model 3 assumed that immunological responses modulate both microbial and metabolic responses while the latter two cross influencing each other.

From the three hypothesized models (Figure 4C), model 3 exhibited significantly $(P<0.05)$ lower Chi- 
square value $(0)$ in comparison with models 1 $(17 \cdot 627)$ and $2(12 \cdot 409)$. The AIC and BIC scores of model 3 were recorded at $4225 \cdot 80$ and $4246 \cdot 80$, respectively. The hypothesized model 3 suggested a causative relationship between immunological parameters vs gut microbial and urine metabolic compositional changes, while a reciprocal relationship occurred between the latter two biological systems.

\section{Correlation between host immune, gut microbial and metabolic responses to $\mathrm{T}$. gondii infection}

Distance based linear modelling was carried out to identify the parameters (within each systems) that exhibited strongest correlation to the corresponding responses. For instance, when we modelled the metabolic pattern using immunological variables, IFN- $\gamma$ was selected as the best explanatory variable which accounted for approximately $5 \%$ of the total variation in the urine metabolic profiles of the experimental animals. However, no immunological parameter was selected when we modelled using gut microbial compositional pattern. On the other hand, changes in formate, glycine and lactate were consistent with the responses observed in gut microbial profiles and explained $\sim 45 \%$ of the variance. Three TRFLP peaks were selected as the parsimonious model for the urine metabolic profiles. However, the taxonomic identity of the three selected TRFs was unknown as no match was obtained when comparing the size of the TRFs with the reference generated through in silico digest of RDP 16S data (Table 3).

\section{DISCUSSION}

The present study characterized cytokine expression levels, metabolic profiles and fecal microbiota profiles of the mammalian host in response to $T$. gondii infection over a period of 42 days. To our best knowledge, this work presented one of the longest longitudinal cross-biological systems monitoring for $T$. gondii infection in a mouse model. Similar previous works were mainly targeting the responses during acute phase (cf. 7-9 days) (Heimesaat et al. 2006; Benson et al. 2009; Molloy et al. 2013) and only a few have extended their studies to understand the host systemic and microbial dynamics in the putative chronic phase (cf. > 20 days) (Arsenijevic et al. 1997; Fenoy et al. 2015). Even when available, the studies were usually focussed on host immunological responses with reduced emphasis given to host-microbiome systemic integration. Using a systems biology approach, we are able to identify the links between the immune-metabolicmicrobial patterns. Additionally, we also proposed a causal model for $T$. gondii infection using the structural equation modelling technique.

Histopathology of haematoxylin and eosin stained paraffinized brain tissues from the current study

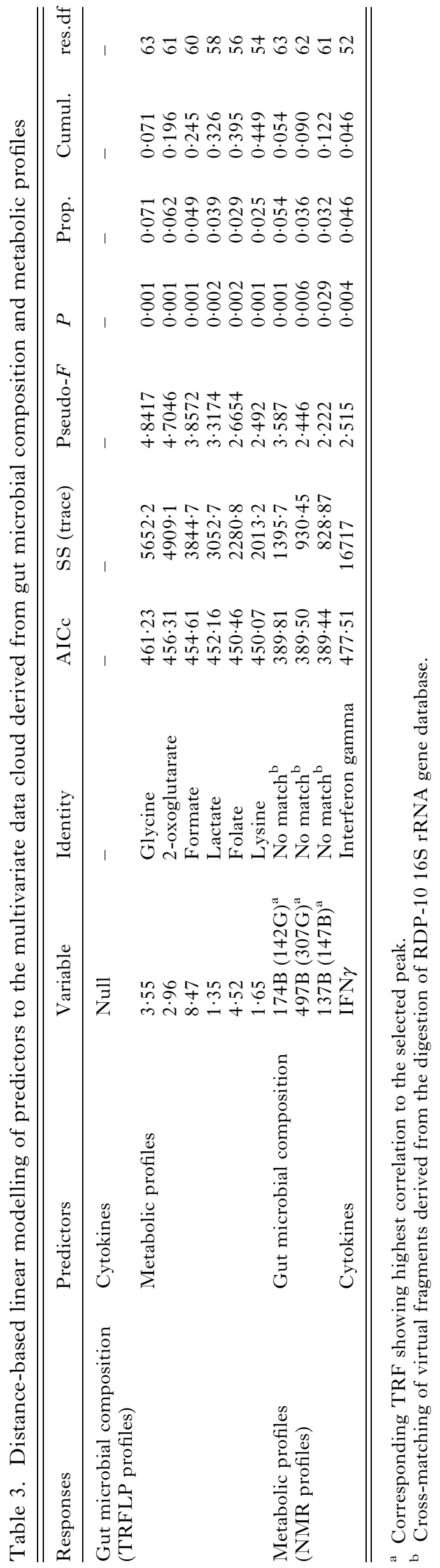


showed that putative chronic infection was established by day 42 represented by brain cysts formation. This is in agreement with previous published works which showed that chronic infection can be established in a mouse model 2-4 weeks post-infection with $T$. gondii ME49 strain (Ferguson et al. 1994a, b; Chew et al. 2012b). However, as bradyzoite-specific genes such as BrayBAG1 and LDH2 were not detected here, the precise development stage is difficult to be ascertained. Nevertheless, the size of the brain cyst (ca. $15 \mu \mathrm{m}$ ) detected in this study is consistent with the chronic phase of other BALB/c mice Toxoplasmosis model (e.g. Chew et al. $2012 a, b, 15-20 \mu \mathrm{m}$ at $2-15$ weeks postinfection; Melzer et al. 2010. 7-20 $\mu \mathrm{m}$ at day 30 post-infection) (Chew et al. 2012b; Melzer et al. 2010).

A myriad of physiological responses had been found to be associated with different phases of $T$. gondii infection. For instance, comparing the energy balance and cytokine gene expression of murine model between acute and chronic $T$. gondii infection, Arsenijevic et al. (1997) showed that elevated TNF- $\alpha$, IL- $1 \beta$, IL-5 and IFN- $\gamma$ coupled with increased energy expenditure were detected as early as day 1 post-infection during acute phase. In contrast, recovery/reduction of energy metabolism and cytokines expression were detected except TNF- $\alpha$ and IL-10. Separately, miR-132, which altered dopamine pathway of the infected mice was also found to be elevated during acute phase (Xiao et al. 2014), while a reduction was detected in the later chronic state ( $\mathrm{Li}$ et al. 2015).

Based on our study, apparent overall immunological modulation was detected on days 7 and 14 post-infection, while recovery to the pre-infection stage was exhibited between days 21 and 42. As observed in the trajectory plot (Figure 2B), the immune response trajectory changes after day 14 indicated a change in host response, indicating the start of chronic infection. This observation is in agreement with previous work conducted in our laboratory which showed that acute infection of $T$. gondii in BALB/c mouse-model lasted for 2 weeks prior to the onset of chronic infection from 2 weeks onwards post infection (Chew et al. 2012b). It also showed the reproducibility of the $T$. gondii ME49infected BALB/c mouse model. Specifically, elevated serum $\mathrm{TNF}-\alpha$, IL-12p40 and IFN- $\gamma$ was prominent during acute infection phase. Among the three cytokines, continued overexpression was only detected for IFN- $\gamma$ in the putative chronic stage. Acute infection of $T$. gondii has been shown to invoke strong host Th1 immune responses (Olguin et al. 2015). In addition, consistent report by Gazzinelli et al. (1993, 1994) showed that IL$12 \mathrm{p} 40$ was detected as early as 2 days post $T$. gondii infection followed by a concomitant increase in IFN- $\gamma$. It has been suggested that $\mathrm{TNF}-\alpha$ induces natural killer cells activity and IFN- $\gamma$ synthesis during $T$. gondii infection (Hunter et al. 1994). On the other hand, Benson et al. (2009) suggested that the production of IL-12 and IFN- $\gamma$ in the dendritic cells of infected animals is stimulated by the gut microflora (Benson et al. 2009). Activation of IL12 dependent IFN- $\gamma$ response during acute $T$. gondii infection was reported to induce the loss of paneth cells and triggers dysbiosis (Raetz et al. 2013). Further, IFN- $\gamma$ was also found to facilitate the delay in $T$. gondii cells growth by inducing the degradation of tryptophan. Further, the cytokine also facilitates protective innate and $\mathrm{T}$ cell immune responses to control cerebral $T$. gondii infection (Sa et al. 2015).

The host immune response to infection can be observed in the urinary metabolic profile represented by changes in urinary glycoproteins specifically $N$-acetyl glutamate. Elevated urinary glycoproteins had been implicated in various diseases (Vivekanandan-Giri et al. 2011) and are currently used as markers of autoimmunity and malignancy. This is not surprising given that glycoproteins are involved in important cell signalling pathways and cell-to-cell interactions (Lowe, 2001). Thus, a change in host physiology due to a disease state will invariably affect these pathways, which can be observed in the urinary metabolic composition. Although only urinary $N$-acetyl glutamate was observed to change in the early phase infection, we postulated the possibility of a temporal delay between the expressions of host immune response translated into host urinary metabolic composition as it involved crossing several biological compartments (Yap et al. 2015). This is further supported by the results obtained on termination time point where urinary $\mathrm{N}$-acetyls and $\mathrm{O}$-acetyls of glycoproteins were lower in the infected group.

Reduced urinary excretion of 2-oxoglutarate, citrate and fumarate indicated perturbed host energy metabolism in response to infection. The tachyzoites of $T$. gondii can infiltrate and proliferate in any mammalian hosts nucleated cells. Like all other intracellular pathogens, T. gondii tachyzoites rely on host carbon sources and essential nutrients to survive (Polonais and Soldati-Favre, 2010). MacRae et al. (2012) showed that T. gondii tachyzoites utilizes glucose as carbon source to generate energy via oxidative tricarboxylic acid cycle, particularly during acute phase infection. In addition, elevated levels of urinary $\alpha$-hydroxy $N$-valerate and $\beta$-aminoisobutyrate are indicative of perturbation in host amino acids catabolism in response to infection. Urinary excretion of these short-chain fatty acids suggested a transient shift in energy metabolism towards oxidation of both gluconeogenic and ketogenic amino acids such as isoleucine, leucine and valine (Harper et al. 1984). Changes in urinary short-chain fatty acids have been reported in 
various disease states, including cytomegalovirus infection (Fanos et al. 2013) and Leishmania infection (Lamour et al. 2015). Further, the increased urinary excretion of creatine with concomitant increase in urinary taurine in the infected animals also indicated a shift in host muscle energy homeostasis (Wang et al. 2008; Fanos et al. 2013).

In the current study, the evenness of fecal microbial composition of the infected animals was lower as compared to the controls during acute infection. Indeed, several authors had reported dysbiosis in gut during acute phase of oral $T$. gondii infection. Possible mechanisms that underlie the changes in gut bacterial community include intestinal pathology (i.e. formation of intestinal casts and loss of paneth cells) and adaptive immunity actions against commensals (Hand et al. 2012; Molloy et al. 2013; Raetz et al. 2013). However, such a difference was not observed in the samples collected on the terminal time point. This could be due to the reduced interactions between $T$. gondii and host gut microbiome as the protozoans begin to encyst in host tissues. Parasitic infections have been shown to affect host gut microbiome diversity (Kay et al. 2015; Lamour et al. 2015). Holzscheiter et al. (2014) showed, in a schistoshome-infected murine model, that excretion of schistosome egg was reduced when the host gut bacteria was depleted with concomitant alteration in immune and inflammatory responses as well as gut pathology. Alteration of host gut microbiome composition after $T$. gondii infection in this study can also be indirectly represented through perturbation in the metabolism of mammalian-microbial co-metabolites namely urinary hippurate, phenyacetylglycine, trimethylamine $N$-oxide, dimethylglycine and acetate. Toxoplasma gondii-induced changes in mouse urine included elevated dimethylglycine and trimethylamine $N$-oxide, which suggested alteration in host gut microbial activity since dimethylglycine and trimethylamine $N$-oxide are intermediates of dietary carnitine and choline, which are degraded to trimethylamine by gut microbe before being transported to the liver and oxidized to trimethylamine $N$-oxide (Smith et al. 1994). In addition, $T$. gondii infection also induced elevated urinary phenylacetylglycine and decreased urinary hippurate. Both phenylacetylglycine and hippurate are known mammalian-microbial co-metabolites (Yap et al. 2015). Nicholls et al. (2001) showed that both hippurate and phenylacetylglycine were absent in the urine of germ-free rats and were only observed several days later after exposure to laboratory environment implicating their link to microbial metabolism. Hippurate is formed in the liver through glycine conjugation of benzoate produced from bacterial metabolism of plant phenols (Schwab et al. 2001). Further, the gut microbiota is involved in breakdown of aromatic amino acids such as tryptophan and tyrosine (Diaz et al. 2001). The significant changes in urinary mammalian-microbial co-metabolites observed in the current study indicated that $T$. gondii infection can induce change in bacterial metabolism of phenolics in mammals.

It is noteworthy that several metabolites had shown a consistent trend in both acute and the putative chronic phase. For instance, upregulation of $\alpha$ hydroxy $N$-valerate and guanidinoacetate were detected in the urinary metabolite profiles on days 14 and 42. Guanidinoacetate has been found to increased acethylcholinesterase activity and brain dysfunction (Zugno et al. 2008). This may indicate the involvement of the metabolite in symptomatic behavioural changes of the disease. Conversely, a consistent reduction in gut microbial-mammalian co-metabolites including phenylacetylglcine and trimethylamine $N$-oxide was detected (Zheng et al. 2011). The strong host metabolic-microbial interaction corroborated with the CAP ordination of TRFLP and NMR profiling where consistent microbial and metabolic clustering at day 14 were recorded (Figures $2 \mathrm{C}$ and $4 \mathrm{~A}$ ).

When compared across Figs. 2, 3 and 4, it is notable that some data points were inconsistent with each other (e.g. cytokines profiles vs TRFLP profiles). The discrepancy was due to overlapping of some of the data points displayed in the respective scores plots with each other under the dimension projected. In addition, during multivariate statistical analyses, some of the outlying samples were removed due to spurious instrumental reading in order to avoid compromising statistical model predictivity and robustness. The actual sample sizes used for different matrices (i.e. metabolic profiles, cytokines profile and TRFLP profiles) are given in Table 2, and Tables S1 and S2 in the Supplementary Materials (available from http://journals.cambridge.org/ PAO).

One major objective in the study of disease progression is to establish sequelae of infection from acute to the putative chronic stages. By comparing the immune-metabolic-microbial patterns, we were able to show that conspicuous immunological alteration occurred earlier (day 7) than host metabolic and microbial modulation (day 14) during acute infection phase. We further established the directionality of the putative causal relationship using structural modelling equation. Based on our model, host metabolism and gut microbial compositional changes were likely to be a function of immunological status (Model 3, Fig. 4C). It is interesting to note that the role of gut microflora in immune regulation towards infection has been well studied (Benson et al. 2009; Caballero and Pamer, 2015). However, the reverse had received little attention. We acknowledged that the model will be more complete if parasites related factor such as cyst size, gene expression pattern is included in the model. 
However, since that the parasitic factors are equal across the three proposed models (Fig. 4C), Model 3 is likely to remain as the best model even if additional factors are included. Using multivariate regression, we also exhibited close interaction between gut microbial and metabolic dynamics. For instance, the $45 \%$ of the variance in TRFLP profiles can be explained by NMR profiles, while $12 \cdot 2 \%$ was explained vice versa (Table 3 ).

\section{Concluding remarks}

The systems biology approach used here to understand the effect of $T$. gondii infection in mammalian host sheds new light into host metabolic as well as host gut microbe responses to infection. Using structural equation modelling, we were able to show statistically the host immune system as the driver for changes observed in host metabolism and gut microbe composition. Clear differences can be observed between acute and the putative chronic phases of $T$. gondii infection represented by host immune responses and host energy metabolism. Furthermore, gut microbe compositional change was observed only during acute phase of infection but not during the chronic phase of infection although significant changes in host metabolism can still be observed during the chronic phase of infection. The metabolites identified during the chronic phase infection warrant further investigations on their potential as diagnostic markers for chronic $T$. gondii infection.

\section{SUPPLEMENTARY MATERIAL}

The supplementary material for this article can be found at http://dx.doi.org/10.1017/pao.2016.8.

\section{ACKNOWLEDGEMENTS}

NMR signal processing and multivariate in-house software was developed by Dr O. Cloarec, Dr T. Ebbels, Dr Kirill A. Veselkov, Dr H. Keun and Dr M. Rantalainen (Biomolecular Medicine, Department of Surgery and Cancer, Imperial College London). The authors also gratefully acknowledge the NMR facilities and assistance provided by Atta-ur-Rahman Institute for Natural Products Discovery, Universiti Teknologi MARA (UiTM), Puncak Alam Campus, Selangor, Malaysia.

\section{FINANCIAL SUPPORT}

This research is funded by the Malaysian Ministry of Science, Technology and Innovation, Science Fund (grant number: 02-02-09-SF0033 - to I.K.S.Y.).

\section{AUTHOR CONTRIBUTIONS}

Conceived and designed the experiments: I.K.S.Y., M.J.W., P.K.C.L. Performed the experiments: K.M.T., I.K.S.Y., S.H.E.L., L.O.D., Y.W.K.
Analysed the data: K.M.T., C.C.W., S.H.E.L., N.I., M.J.W., I.K.S.Y. Contributed reagents/materials/analysis tools: C.C.W., S.H.E.L., N.I., M.J. W., I.K.S.Y. Wrote the paper: K.M.T., C.C.W., S.H.E.L., I.K.S.Y.

\section{CONFLICT OF INTEREST DISCLOSURE}

The authors declare no competing financial interest.

\section{REFERENCES}

Anderson, M. J. and Willis, T. J. (2003). Canonical analysis of principal coordinates: a useful method of constrained ordination for ecology. Ecology 84, 511-525.

Arsenijevic, D., Girardier, L., Seydoux, J., Chang, H. R. and Dulloo, A. G. (1997). Altered energy balance and cytokine gene expression in a murine model of chronic infection with Toxoplasma gondii. American Fournal of Physiology 272, E908-E917.

Benson, A., Pifer, R., Behrendt, C. L., Hooper, L. V. and Yarovinsky, F. (2009). Gut commensal bacteria direct a protective immune response against Toxoplasma gondii. Cell Host \& Microbe 6, 187-196. Boyle, J. P., Saeij, J. P., Cleary, M. D. and Boothroyd, J. C. (2006). Analysis of gene expression during development: lessons from the Apicomplexa. Microbes and Infection 8, 1623-1630.

Caballero, S. and Pamer, E. G. (2015). Microbiota-mediated inflammation and antimicrobial defense in the intestine. Annual Review of Immunology 33, 227-256.

Canuto, G. A., Castilho-Martins, E. A., Tavares, M. F., Rivas, L., Barbas, C. and Lopez-Gonzalvez, A. (2014). Multi-analytical platform metabolomic approach to study miltefosine mechanism of action and resistance in Leishmania. Analytical and Bioanalytical Chemistry 406, 34593476

Chew, W. K., Segarra, I., Ambu, S. and Mak, J. W. (2012a). Significant reduction of brain cysts caused by Toxoplasma gondii after treatment with spiramycin coadministered with metronidazole in a mouse model of chronic toxoplasmosis. Antimicrobial Agents and Chemotherapy 56, 1762 1768

Chew, W. K., Wah, M. J., Ambu, S. and Segarra, I. (2012b). Toxoplasma gondii: determination of the onset of chronic infection in mice and the in vitro reactivation of brain cysts. Experimental Parasitology 130, 22-25.

Chong, C. W., Pearce, D. A., Convey, P. and Tan, I. K. P. (2012). The identification of environmental parameters which could influence soil bacterial community composition on the Antarctic Peninsula - a statistical approach. Antarctic Science 24, 249-258.

Cloarec, O., Dumas, M. E., Trygg, J., Craig, A., Barton, R. H., Lindon, J. C., Nicholson, J. K. and Holmes, E. (2005). Evaluation of the orthogonal projection on latent structure model limitations caused by chemical shift variability and improved visualization of biomarker changes in $1 \mathrm{H}$ NMR spectroscopic metabonomic studies. Analytical Chemistry 77, 517-526.

Culman, S. W., Bukowski, R., Gauch, H. G., Cadillo-Quiroz, H. and Buckley, D. H. (2009). T-REX: software for the processing and analysis of T-RFLP data. BMC Bioinformatics 10, 171.

Diaz, E., Ferrandez, A., Prieto, M. A. and Garcia, J. L. (2001) Biodegradation of aromatic compounds by Escherichia coli. Microbiology and Molecular Biology Reviews 65, 523-569.

Epskamp, S. (2015). SemPlot: unified visualizations of structural equation models. Structural Equation Modeling 22, 474-483.

Fanos, V., Locci, E., Noto, A., Lazzarotto, T., Manzoni, P., Atzori, L. and Lanari, M. (2013). Urinary metabolomics in newborns infected by human cytomegalovirus: a preliminary investigation. Early Human Development 89 (Suppl 1), S58-S61.

Fenoy, I. M., Sanchez, V. R., Soto, A. S., Picchio, M. S., Martin, V. and Goldman, A. (2015). Toxoplasma gondii infection modulate systemic allergic immune response in BALB/c mice. Experimental Parasitology 154, $47-50$.

Ferguson, D. J., Huskinson-Mark, J., Araujo, F. G. and Remington, J. S. (1994a). A morphological study of chronic cerebral toxoplasmosis in mice: comparison of four different strains of Toxoplasma gondii. Parasitology Research 80, 493-501.

Ferguson, D. J., Huskinson-Mark, J., Araujo, F. G. and Remington, J. S. (1994b). An ultrastructural study of the effect of treatment with 
atovaquone in brains of mice chronically infected with the ME49 strain of Toxoplasma gondii. International Fournal of Experimental Pathology 75, 111-116.

Fiorentino, D. F., Zlotnik, A., Mosmann, T. R., Howard, M. and O'Garra, A. (1991). IL-10 inhibits cytokine production by activated macrophages. Fournal of Immunology 147, 3815-3822.

Gazzinelli, R. T., Hieny, S., Wynn, T. A., Wolf, S. and Sher, A. (1993). Interleukin 12 is required for the T-lymphocyte-independent induction of interferon gamma by an intracellular parasite and induces resistance in Tcell-deficient hosts. Proceedings of the National Academy of Sciences of the United States of America 90, 6115-6119.

Gazzinelli, R. T., Wysocka, M., Hayashi, S., Denkers, E. Y., Hieny, S., Caspar, P., Trinchieri, G. and Sher, A. (1994). Parasiteinduced IL-12 stimulates early IFN-gamma synthesis and resistance during acute infection with Toxoplasma gondii. Fournal of Immunology 153, 2533-2543. Hakim, F. T., Gazzinelli, R. T., Denkers, E., Hieny, S., Shearer, G. M. and Sher, A. (1991). $\mathrm{CD}^{+} \mathrm{T}$ cells from mice vaccinated against Toxoplasma gondii are cytotoxic for parasite-infected or antigen-pulsed host cells. Fournal of Immunology 147, 2310-2316.

Hand, T. W., Dos Santos, L. M., Bouladoux, N., Molloy, M. J., Pagan, A. J., Pepper, M., Maynard, C. L., Elson, C. O., III and Belkaid, Y. (2012). Acute gastrointestinal infection induces long-lived microbiota-specific T cell responses. Science 337, 1553-1556.

Harper, A. E., Miller, R. H. and Block, K. P. (1984). Branched-chain amino acid metabolism. Annual Review of Nutrition 4, 409-454.

Heimesaat, M. M., Bereswill, S., Fischer, A., Fuchs, D., Struck, D., Niebergall, J., Jahn, H. K., Dunay, I. R., Moter, A., Gescher, D. M., Schumann, R. R., Gobel, U. B. and Liesenfeld, O. (2006). Gram-negative bacteria aggravate murine small intestinal Th1-type immunopathology following oral infection with Toxoplasma gondii. Fournal of Immunology 177, 8785-8795.

Holzscheiter, M., Layland, L. E., Loffredo-Verde, E., Mair, K., Vogelmann, R., Langer, R., Wagner, H. and Prazeres da Costa, C. (2014). Lack of host gut microbiota alters immune responses and intestinal granuloma formation during schistosomiasis. Clinical and Experimental Immunology 175, 246-257.

Hunter, C. A., Subauste, C. S., Van Cleave, V. H. and Remington, J. S. (1994). Production of gamma interferon by natural killer cells from Toxoplasma gondii-infected SCID mice: regulation by interleukin-10, interleukin-12, and tumor necrosis factor alpha. Infection and Immunity 62, 2818-2824

Kay, G. L., Millard, A., Sergeant, M. J., Midzi, N., Gwisai, R., Mduluza, T., Ivens, A., Nausch, N., Mutapi, F. and Pallen, M. (2015). Differences in the faecal microbiome in Schistosoma haematobium infected children vs uninfected children. PLoS Neglected Tropical Disease 9, e0003861.

Kim, K. and Weiss, L. M. (2008). Toxoplasma: the next 100 years. Microbes and Infection 10, 978-984.

Lamour, S. D., Veselkov, K. A., Posma, J. M., Giraud, E., Rogers, M. E., Croft, S., Marchesi, J. R., Holmes, E., Seifert, K. and Saric, J. (2015). Metabolic, immune, and gut microbial signals mount a systems response to Leishmania major infection. Fournal of Proteome Research 14, 318-329. Li, Y. E., Kannan, G., Pletnikov, M. V., Yolken, R. H. and Xiao, J. (2015). Chronic infection of Toxoplasma gondii downregulates miR-132 expression in multiple brain regions in a sex-dependent manner. Parasitology 142, 623-632.

Lowe, J. B. (2001). Glycosylation, immunity, and autoimmunity. Cell 104, 809-812.

MacRae, J. I., Sheiner, L., Nahid, A., Tonkin, C., Striepen, B. and McConville, M. J. (2012). Mitochondrial metabolism of glucose and glutamine is required for intracellular growth of Toxoplasma gondii. Cell Host \& Microbe 12, 682-692.

Melzer, T. C., Cranston, H. J., Weiss, L. M. and Halonen, S. K. (2010). Host cell preference of Toxoplasma gondii cysts in murine brain: a confocal study. Fournal of Neuroparasitology 1, N100505. doi: 10.4303/jnp/N100505. Molloy, M. J., Grainger, J. R., Bouladoux, N., Hand, T. W., Koo, L. Y., Naik, S., Quinones, M., Dzutsev, A. K., Gao, J. L., Trinchieri, G., Murphy, P. M. and Belkaid, Y. (2013). Intraluminal containment of commensal outgrowth in the gut during infectioninduced dysbiosis. Cell Host $\&^{\circ}$ Microbe 14, 318-328.

Montoya, J. G. and Liesenfeld, O. (2004). Toxoplasmosis. Lancet 363, 1965-1976.

Nicholls, A. W., Holmes, E., Lindon, J. C., Shockcor, J. P., Farrant, R. D., Haselden, J. N., Damment, S. J., Waterfield, C. J. and Nicholson, J. K. (2001). Metabonomic investigations into hydrazine toxicity in the rat. Chemical Research in Toxicology 14, 975-987.

Olguin, J. E., Fernandez, J., Salinas, N., Juarez, I., RodriguezSosa, M., Campuzano, J., Castellanos, C. and Saavedra, R. (2015). Adoptive transfer of $\mathrm{CD} 4{ }^{(+)} \mathrm{Foxp}^{(+)}$regulatory $\mathrm{T}$ cells to $\mathrm{C} 57 \mathrm{BL} / 6 \mathrm{~J}$ mice during acute infection with Toxoplasma gondii down modulates the exacerbated Th1 immune response. Microbes and Infection 17, 586-595.

Polonais, V. and Soldati-Favre, D. (2010). Versatility in the acquisition of energy and carbon sources by the Apicomplexa. Biology of the Cell 102, 435-445. Raetz, M., Hwang, S. H., Wilhelm, C. L., Kirkland, D., Benson, A., Sturge, C. R., Mirpuri, J., Vaishnava, S., Hou, B., Defranco, A. L., Gilpin, C. J., Hooper, L. V. and Yarovinsky, F. (2013). Parasiteinduced TH1 cells and intestinal dysbiosis cooperate in IFN-gamma-dependent elimination of Paneth cells. Nature Immunology 14, 136-142. Rosseel, Y. (2012). Lavaan: an R package for structural equation modeling. Fournal of Statistical Software, 48, 1-36.

Sa, Q., Ochiai, E., Tiwari, A., Perkins, S., Mullins, J., Gehman, M., Huckle, W., Eyestone, W. H., Saunders, T. L., Shelton, B. J. and Suzuki, Y. (2015). Cutting edge: IFN-gamma produced by brain-resident cells is crucial to control cerebral infection with Toxoplasma gondii. Fournal of Immunology 195, 796-800.

Schwab, A. J., Tao, L., Yoshimura, T., Simard, A., Barker, F. and Pang, K. S. (2001). Hepatic uptake and metabolism of benzoate: a multiple indicator dilution, perfused rat liver study. American fournal of Physiology. Gastrointestinal and Liver Physiology 280, G1124-G1136.

Smith, J. L., Wishnok, J. S. and Deen, W. M. (1994). Metabolism and excretion of methylamines in rats. Toxicology and Applied Pharmacology 125, 296-308.

Smith, C. J., Danilowicz, B. S., Clear, A. K., Costello, F. J., Wilson, B. and Meijer, W. G. (2005). T-Align, a web-based tool for comparison of multiple terminal restriction fragment length polymorphism profiles. FEMS Microbiology Ecology 54, 375-380.

Tenter, A. M., Heckeroth, A. R. and Weiss, L. M. (2000). Toxoplasma gondii: from animals to humans. International Fournal for Parasitology $\mathbf{3 0}$, 1217-1258.

Trygg, J. and Wold, S. (2002). Orthogonal projections to latent structures (O-PLS). Fournal of Chemometrics 16, 119-128.

Turunen, H., Vuorio, K. A. and Leinikki, P. O. (1983). Determination of $\operatorname{IgG}, \operatorname{IgM}$ and $\operatorname{IgA}$ antibody responses in human toxoplasmosis by enzyme-linked immunosorbent assay (ELISA). Scandinavian Fournal of Infectious Diseases 15, 307-311.

Vivekanandan-Giri, A., Slocum, J. L., Buller, C. L., Basrur, V., Ju, W., Pop-Busui, R., Lubman, D. M., Kretzler, M. and Pennathur, S. (2011). Urine glycoprotein profile reveals novel markers for chronic kidney disease. International Fournal of Proteomics 214715, 10.

Wang, Y., Holmes, E., Nicholson, J. K., Cloarec, O., Chollet, J., Tanner, M., Singer, B. H. and Utzinger, J. (2004). Metabonomic investigations in mice infected with Schistosoma mansoni: an approach for biomarker identification. Proceedings of the National Academy of Sciences of the USA 101, 12676-12681.

Wang, Y., Utzinger, J., Xiao, S. H., Xue, J., Nicholson, J. K., Tanner, M., Singer, B. H. and Holmes, E. (2006). System level metabolic effects of a Schistosoma japonicum infection in the Syrian hamster. Molecular and Biochemical Parasitology 146, 1-9.

Wang, Y., Utzinger, J., Saric, J., Li, J. V., Burckhardt, J., Dirnhofer, S., Nicholson, J. K., Singer, B. H., Brun, R. and Holmes, E. (2008). Global metabolic responses of mice to Trypanosoma brucei brucei infection. Proceedings of the National Academy of Sciences of the United States of America 105, 6127-6132.

Wong, S. Y. and Remington, J. S. (1993). Biology of Toxoplasma gondii. AIDS 7, 299-316.

Xiao, J., Li, Y., Prandovszky, E., Karuppagounder, S. S., Talbot, C. C., Jr., Dawson, V. L., Dawson, T. M. and Yolken, R. H. (2014). MicroRNA-132 dysregulation in Toxoplasma gondii infection has implications for dopamine signaling pathway. Neuroscience 268, 128-138.

Yanagihara, H., Kamo, K.-I. and Tonda, T. (2011). Second-order biascorrected AIC in multivariate normal linear models under non-normality. Canadian Fournal of Statistics 39, 126-146.

Yap, I. K., Kho, M. T., Lim, S. H., Ismail, N. H., Yam, W. K. and Chong, C. W. (2015). Acclimatisation-induced stress influenced host metabolic and gut microbial composition change. Molecular Biosystems 11, 297-306. Zheng, X., Xie, G., Zhao, A., Zhao, L., Yao, C., Chiu, N. H., Zhou, Z., Bao, Y., Jia, W., Nicholson, J. K. and Jia, W. (2011). The footprints of gut microbial-mammalian co-metabolism. Fournal of Proteome Research 10, 5512-5522.

Zhou, X. W., Blackman, M. J., Howell, S. A. and Carruthers, V. B. (2004). Proteomic analysis of cleavage events reveals a dynamic two-step mechanism for proteolysis of a key parasite adhesive complex. Molecular ङ Cellular Proteomics 3, 565-576.

Zugno, A. I., Pereira, L. O., Mattos, C., Scherer, E. B., Netto, C. A. and Wyse, A. T. (2008). Guanidinoacetate administration increases acetylcholinesterase activity in striatum of rats and impairs retention of an inhibitory avoidance task. Metabolic Brain Disease 23, 189-198. 